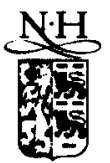

ELSEVIER

\title{
Who benefits from antidumping legislation?
}

\author{
Simon P. Anderson ${ }^{\mathrm{a}, *}$, Nicolas Schmitt ${ }^{\mathrm{b}}$, Jacques-François Thisse ${ }^{\mathrm{c}}$ \\ ${ }^{a}$ Department of Economics, University of Virginia, Charlottesville, VA 22901, USA \\ ${ }^{\mathrm{b}}$ Department of Economics, Simon Fraser University, Burnaby, BC V5A 1 S6 Canada \\ 'Université de Paris I-Sorbonne and CERAS-ENPC, 28 Rue des Saints-Peres, F-75343, \\ Paris, Cedex 07, France
}

Received July 1992, revised version received March 1994

\begin{abstract}
Antidumping laws alter the pricing policies of foreign firms to the benefit of domestic ones. Unilaterally, domestic firms want to lobby for antidumping restrictions; unilaterally, consumers want to lobby against them. This paper shows that if firms succeed in both countries, their profits fall and consumer surplus rises, so that firms end up working for consumers everywhere by lobbying. It also shows that each government, maximizing total domestic surplus, prefers no legislation irrespective of the action of another government. However, world surplus may be greater with antidumping rules. These results hold under both Bertrand and Cournot competition.
\end{abstract}

Key words: Antidumping law; Dumping; Market integration; Market segmentation; Trade policy

JEL classification: F12; F13; K29; L13

\section{Introduction}

The reductions in tariffs over the past 40 years have led governments to resort to other practices which constrain trade, and the restriction that is most often applied is antidumping law (Jackson and Vermulst, 1989). Our objective is to analyze the incentives for governments to impose antidump-

* Corresponding author. 
ing laws and to determine who benefits from them. We are particularly interested in determining what happens when government can legislate whether or not foreign firms can dump. In contrast to most studies, antidumping legislation is viewed as the outcome of strategic interaction between governments.

We use a variant of the reciprocal dumping model of Brander and Krugman (1983) to characterize firm rivalry. Thus dumping arises from the demand side (see Gruenspecht, 1988, for a cost side analysis with learning by doing). Governments choose whether or not to impose antidumping laws, thus determining the pricing policy of foreign firms. When governments choose, they anticipate the effects of such laws on the market equilibrium.

We find that the non-cooperative equilibrium is to impose no law if governments unilaterally maximize domestic welfare. However, welfare might be improved if laws were used when the barrier to trade involves resource costs, but not if the barrier is a transfer (such as a tariff). Hence tariffs and transport costs play different roles in the model, in contrast to the standard view of tariffs as administrative transport costs.

Firms benefit if an antidumping law is imposed unilaterally on rival firms, so they are tempted to lobby for a law. ${ }^{1}$ However, profits fall if laws are bilaterally imposed. Instead, consumers gain.

In a recent paper, Bian and Gaudet (1992) analyze a similar two-stage game (with Cournot competition at the second stage) between governments that act to maximize welfare by choosing countervailing duty (CVD) rates that depend on the dumping margin. Such trade policy is continuous, in contrast to the all-or-nothing policies we consider. In practice, CVDs are only imposed after a firm has been found guilty of dumping. Moreover, a CVD is only one of several possible outcomes following the initiation of an antidumping case. Another frequent outcome is a 'price undertaking', that is, 'a binding commitment... to raise export prices so that either the dumping or the injury suffered from the dumped imports by the domestic industry is eliminated' (GATT, 1991, p. 74). ${ }^{2}$ At this level, our analysis can be viewed as describing the complete elimination of dumping margins through price undertakings; Bian and Gaudet (1992) provide a complemen-

\footnotetext{
${ }^{1}$ Staiger and Wolak (1989) argue that antidumping laws facilitate tacit international collusion. This also suggests that domestic firms have an incentive to lobby for such rules.

${ }^{2}$ In the United States, from 1980 through 1985 , only 27 percent of the 300 antidumping cases initiated resulted in countervailing duties, whereas 38 percent were withdrawn (Prusa, 1992, Table 1, p. 5). Prusa (1992) suggests that many of the cases withdrawn (80 percent according to Vermulst, 1987) were done so because settlement was reached, usually with price undertakings or quantity restrictions. The figures are similar for the EC. In 179 of 249 affirmative cases between 1980 and 1987, foreign firms agreed to price undertakings or volume undertakings and CVDs were imposed in 70 cases (Tharakan, 1991, Table 1, p. 1343).
} 
tary analysis of the CVD case. However, insofar as many firms generally comply with laws (and non-compliance may lead to costly litigation and penalties), our paper addresses the broader and more fundamental issue of whether the law should exist in the first place.

Since there is a formal equivalence in our model between price discrimination and dumping, the analysis also applies to legislation forbidding price discrimination. This paper therefore contributes to the debate about price discrimination legislation within the EC, NAFTA, etc. In 1983, the European Commission published a draft regulation on the application of Article 85 of the Rome Treaty in which it proposed to introduce bounds on price differentials between members for some key industries like automobiles (see Mertens and Ginsburgh, 1985, and Davidson et al., 1989, for more details). ${ }^{3}$ We look at the incentives to unilaterally introduce rules forbidding price discrimination, and the possible gains from bilateral agreements between governments. In particular, the analysis explains the gains from bilateral agreements between governments to avoid prisoners' dilemma situations.

The model is presented in the next section. In Section 3 we compare the (subgame) equilibria in which both firms segment or tie their prices in the two markets. Section 4 looks at the remaining (cross case) subgame and solves the game between governments. It also argues that the results for a Cournot market game are the same as those for the Bertrand game. Section 5 concludes.

\section{The model}

There are two identical countries; domestic, D, and foreign, $F$, with respective governments, $G_{\mathrm{D}}$ and $G_{\mathrm{F}}$. There are two firms: firm 1 produces product 1 in $\mathrm{D}$, and firm 2 produces product 2 in $\mathrm{F}$. Let $p_{i}$ denote the consumer price of product $i$ in $\mathrm{D}$, and $p_{i}^{*}$ denote its consumer price in $\mathrm{F}$, $i=1,2$. Similarly, $q_{i}$ and $q_{i}^{*}$ denote producer prices. Markets are separated by a barrier to trade of size $t$ per unit shipped between them. The trade barrier is the same size in each direction, and can be either a transport cost or a tariff.

We consider the subgame perfect Nash equilibrium of a two-stage game. In the first stage each government simultaneously chooses whether or not to enact antidumping laws; so the strategy space for $G_{\mathrm{D}}$ and $G_{\mathrm{F}}$ is $\{l a w$, no $l a w\}$. We consider several alternative government objective functions, as described in Section 4. In the second stage of the game, firms simultaneously set prices to maximize profits subject to any constraints that have been imposed by the governments in the first stage. If $G_{\mathrm{D}}$ chooses no law, firm 2

\footnotetext{
${ }^{3}$ A similar current debate in the United States concerns drug pricing.
} 
chooses $p_{2}$ and $p_{2}^{*}$ without restriction, and firm 2 will be said to segment its market (a pricing policy we call $S$ ). If $G_{\mathrm{D}}$ chooses law, firm 2 chooses $p_{2}$ and $p_{2}^{*}$ subject to the constraint $p_{2} \geqslant p_{2}^{*}+t$, and firm 2's markets will be tied (pricing policy $T$ ). Firm 1's strategies depend on $G_{\mathrm{F}}$ 's action in a similar way (the constraint is $p_{1}^{*} \geqslant p_{1}+t$ if $G_{\mathrm{F}}$ chooses law).

In what follows, we let $(S, T)$ denote the case in which firm 1 segments and firm 2 ties, and $(S, T)$ corresponds to the choice $\{$ no law, law $\}$ by $\left\{G_{\mathrm{F}}, G_{\mathrm{D}}\right\}$, etc. Production costs are constant and equal for both firms. Without loss of generality we henceforth set them cqual to zero.

The demand model is one of differentiated products. Compared with a homogeneous product specification, this has the advantage of ensuring equilibria in pure price strategies if the degree of product heterogeneity is large enough. By contrast, when products are perfect substitutes, the only equilibria for the tied markets game involve mixed strategies (see Fisher and Wilson 1988, and Venables, 1990a).

Demand is modelled by reference to a representative consumer, identical in each country. The indirect utility function is

$$
V\left(p_{1}, p_{2}, Y\right)=-a\left(p_{1}+p_{2}\right)+\frac{b}{2}\left(p_{1}^{2}+p_{2}^{2}\right)-c p_{1} p_{2}+Y,
$$

with $a>0, b \geqslant c>0$, where $Y$ is income and the $p$ 's are the (consumer) prices of the two goods. The form (1) is chosen linear in income, so there are no income effects. It also represents a second-order approximation of a more general symmetric utility function of the form $V\left(p_{1}, p_{2}\right)+Y$. The demands associated with (1) are given by Roy's identity as

$$
x_{i}=a-b p_{i}+c p_{j}, \quad i, j=1,2, i \neq j .
$$

Demands are independent for $c=0$. As $c$ rises, products become closer substitutes. For $c=b$, the total market demand (for both products) is independent of prices; and each firm's demand depends only upon price differences. This is the aggregate demand structure generated from a product differentiation model of the Hotelling (1929) form, in which products are viewed as being located at the extreme points of a onedimensional characteristics space over which consumer tastes are uniformly distributed. In this case, $a$ is viewed as the size of the market and $b$ is inversely proportional to the degree of product heterogeneity (so products become perfect substitutes as $b \rightarrow \infty$ ). As $c$ falls from $b$, the total demand becomes more elastic, and we impose $b \geqslant c>0$ to ensure that products are substitutes with the own demand effect exceeding the cross effect.

An important property of (1) is:

Property 1. The indirect utility function is increasing in the price difference $\Delta \equiv\left|p_{1}-p_{2}\right|$ for a given average price $\bar{p} \equiv\left(p_{1}+p_{2}\right) / 2$. 
To prove this property it suffices to rewrite (1) as

$$
V=-2 a \bar{p}+(b-c) \bar{p}^{2}+\left(\frac{b+c}{4}\right) \Delta^{2}+Y .
$$

Property 1 is a general property of symmetric indirect utility functions, and follows from the quasiconvexity of the indirect utility function. ${ }^{4}$ The result is also reminiscent of the fact that expected utility rises with an increasing mean-preserving spread of price.

\section{Segmented vs. tied (or integrated) markets}

In this section we compare the (symmetric) cases of bilateral market segmentation and bilateral market tying (integrated markets). These cases correspond respectively to the second-stage equilibria induced by both governments having chosen $\{$ no law, no law $\}$ and $\{l a w, l a w\}$ in the first stage.

When markets are segmented the price equilibrium can be determined separately for each market. The profit of firm 1 in market $\mathrm{D}$ is $p_{1}\left(a-b p_{1}+\right.$ $\left.c p_{2}\right)$, and $\left(p_{1}^{*}-t\right)\left(a-b p_{1}^{*}+c p_{2}^{*}\right)$ in market $F$. Clearly the unique Nash price equilibrium is symmetric, with

$$
p_{1}=p_{2}^{*}=\frac{a}{2 b-c}+\frac{c b t}{(2 b-c)(2 b+c)}
$$

and

$$
p_{2}=p_{1}^{*}=\frac{a}{2 b-c}+\frac{2 b^{2} t}{(2 b-c)(2 b+c)} .
$$

The equilibrium price difference within a market is

$$
p_{2}-p_{1}=p_{1}^{*}-p_{2}^{*}=\frac{b t}{2 b+c},
$$

which shows that there is freight absorption, or reciprocal dumping (Brander and Krugman, 1983). Note that the restriction $t<\hat{t}=(2 b+c) a /\left(2 b^{2}-\right.$ $c^{2}$ ) is required for there to be intraindustry trade. This restriction ensures positive producer prices as well as positive demands in each market for both products. The equilibrium profit with market segmentation $(S, S)$ is

\footnotetext{
${ }^{4}$ This result is easily seen by sketching standard convex indifference curves in $\left(p_{1}, p_{2}\right)$ space. By symmetry, these curves are tangent to iso-average price lines at $p_{1}=p_{2}$ and indifference curves closer to the origin correspond to higher (indirect) utility levels.

${ }^{5}$ This inequality is obtained by checking that both firms find it profitable to sell in each market. It implies that $b$ cannot be 'too large'. When $b=c$, the condition reduces to $t<3 a / b$.
} 


$$
\pi_{1}^{S}=\pi_{2}^{S}=b\left[p_{1}^{2}+\left(p_{1}^{*}-t\right)^{2}\right] .
$$

When the two markets are tied through a cost pass-on, and each firm serves both markets, the profit of firm $i$ is

$$
\pi_{i}=q_{i}\left(a-b q_{i}+c\left[q_{j}+t\right]\right)+q_{i}^{*}\left(a-b\left[q_{i}^{*}+t\right]+c q_{j}^{*}\right), \quad i=1,2, i \neq j,
$$

where $q_{i}$ and $q_{j}$ are producer prices and $q_{i}^{*} \geqslant q_{i}, q_{j}^{*} \leqslant q_{j}$ since markets are tied. The candidate symmetric equilibrium is

$$
q_{1}=q_{2}=\frac{2 a-(b-c) t}{2(2 b-c)} .
$$

It is readily checked that the tying constraint is strictly binding at these prices - each firm would prefer to pass on less than $t$. The equilibrium profit with tied markets $(T, T)$ is

$$
\pi_{i}^{T}=2 b q_{i}^{2}, \quad i=1,2 .
$$

For (9) to be an equilibrium, each firm's demand must be non-negative in each market. This requires that

$$
t \leqslant 2 a b /\left(3 b^{2}-c^{2}\right) \text {. }
$$

There is another issue regarding the possible non-existence of equilibrium here. If constrained to tie, a firm may wish to give up entirely on the foreign market in order to raise its domestic price. For a given degree of product heterogeneity, higher $t$ leads to more incentive to stop trading. It can be shown that (9) is an equilibrium for $t$ low enough, and we henceforth assume that the corresponding condition is met. ${ }^{6}$ While this assumption pushes aside some interesting questions (characterization of mixed strategy equilibria, whether one type of pricing is more conducive to trade, etc.), it does enable us to concentrate on trade issues without having to deal with complex price equilibria.

The equilibria under tied and segmented markets can now be compared. An important property of the equilibria is

Property 2. The average consumer price for the products of each firm (and therefore for the products in each country) is the same for both segmented and tied markets, and is given by $\bar{p}=(2 a+b t) / 2(2 b-c)$. The total quantity produced by each firm, $\chi$, is also the same.

The price property follows directly from (4), (5), and (9). To see the

${ }^{6}$ Details are available from the authors on request. 
quantity property, define $\chi \equiv x_{1}+x_{1}^{*}=2 a-b\left(p_{1}+p_{1}^{*}\right)+c\left(p_{2}+p_{2}^{*}\right)=x_{2}+$ $x_{2}^{*}=2 a-b\left(p_{2}+p_{2}^{*}\right)+c\left(p_{1}+p_{1}^{*}\right)$. Hence, the total quantity produced by each firm $(\chi)$ is the same in both segmented and tied markets since the average consumer price is the same?

Proposition 1. Profits are greater under market segmentation than under tied markets.

Proof. From Property 2 the profit per firm is $(\bar{p}-t / 2) \chi$ under tied markets, and $(\bar{p}-\lambda t) x_{1}+(\bar{p}+t(\lambda-1)) x_{1}^{*}$, with $\lambda<1 / 2$ for segmented markets. Profits are greater in $(S, S)$ than in $(T, T)$ since $x_{1}>x_{1}^{*}, \lambda<1 / 2$, and $x_{1}+x_{1}^{*}=\chi$.

It can be shown that joint profits are maximized when firms are required to pass on $\lambda=1 / 2$; and that the equilibrium profit is symmetric in the rate of pass-on around $1 / 2$. It is therefore not surprising that tied markets $(\lambda=1)$ are less profitable than segmented ones $(\lambda \in(0,1 / 2))$ since the tied market involves greater deviation from the maximizing one and segmentation involves too little pass-on. Although firms individually prefer to segment markets when the alternative is to tie them, they collectively prefer an intermediate level of price discrimination (see also Venables, 1990b).

Results for consumer benefits and social surplus are summarized in the following proposition.

Proposition 2. (i) Consumer surplus is greater under tied markets;

(ii) social surplus is greater under tied markets if the trade barrier is a pure resource cost (e.g. a transport cost); and greater under segmented markets if the barrier is a pure transfer (e.g. a tariff).

Proof. (i) This follows directly from Properties 1 and 2, since the average price is the same in both cases but the spread is greater under tied markets (and consumers prefer greater spread for a given average price).

(ii) In the transport cost case, social welfare in country D is

$$
W=V\left(p_{1}, p_{2}\right)+Y+p_{1} x_{1}+\left(p_{1}^{*}-t\right) x_{1}^{*} .
$$

\footnotetext{
${ }^{7}$ Property 2 also extends to the case where firms must pass on a given fraction, $\lambda$, of their transport costs. The profit function in this case becomes $\pi_{i}=q_{i}\left(a-b q_{i}+c\left(q_{j}+\lambda t\right)\right)+\left(q_{i}+\right.$ $\lambda t-t)\left(a-b\left[q_{i}+\lambda t\right]+c q_{j}\right), i, j=1,2, i \neq j$. The (symmetric) solution to this problem shows that average producer and consumer prices are independent of $\lambda$. Note that $\lambda=1$ corresponds to tied markets and $\lambda=b /(2 b+c)$ corresponds to segmented markets [see (6)].
} 
By symmetry, $p_{1}^{*}=p_{2}$ and $x_{1}^{*}=x_{2}$, so, using Roy's identity,

$$
W=V\left(p_{1}, p_{2}\right)+Y-p_{1} V_{1}-\left(p_{2}-t\right) V_{2},
$$

where $V_{i}$ denotes the partial derivative of $V$ with respect to $p_{i}(i=1,2)$.

In comparing tied and segmented markets equilibria, the average consumer price is the same but the spread is higher for tied markets. We therefore consider the derivative of $W$ with respect to $p_{1}$, and impose $\mathrm{d} p_{1}=-\mathrm{d} p_{2}$, to get

$$
\begin{aligned}
\left.\frac{\mathrm{d} W}{\mathrm{~d} p_{1}}\right|_{\mathrm{d} p_{1}=-\mathrm{d} p_{2}} & =p_{1}\left[V_{21}-V_{11}\right]+\left(p_{2}-t\right)\left[V_{22}-V_{21}\right] ; \\
& =(b+c)\left(p_{2}-t-p_{1}\right) .
\end{aligned}
$$

Since $p_{2}-t=p_{1}$ for tied markets, $\mathrm{d} W / \mathrm{d} p_{1}=0$, indicating a maximum.

If $t$ is a specific tariff, a term $t x_{2}$ must be added to (12) representing tariff revenue. The welfare derivative then becomes

$$
\left.\frac{\mathrm{d} W}{\mathrm{~d} p_{1}}\right|_{\mathrm{d} p_{1}=-\mathrm{d} p_{2}}=(b+c)\left(p_{2}-p_{1}\right),
$$

which is positive since $p_{2}>p_{1}$ in market $D$. An increase in $p_{1}$ corresponds to a smaller spread. Hence welfare is higher with market segmentation than with tied markets.

The welfare result for both cases is essentially that, given equal average consumer prices in both scenarios, the prices should differ by the marginal social cost. This cost is $t$ when it is a real resource barricr (transport cost), and zero when the barrier is a transfer (tariff).

Smith and Venables (1988) compare segmented and tied markets in a calibrated partial equilibrium model in order to analyze the effects of the European integration. In accordance with Propositions 1 and 2, they find that firms lose and consumers gain in a move from segmented to tied markets.

\section{Segmented or tied markets?}

To determine the equilibrium of the first-stage game between governments, we must also look at the equilibrium of the subgame in which one firm ties its prices and the other segments its markets. Suppose that firm 1 chooses its prices freely, whereas firm 2 is tied to passing on $t$. We refer to this case as $(S, T)$ or as the cross case.

Firm 1 earns $p_{1}\left(a-b p_{1}+c\left[q_{2}+t\right]\right)$ from market $\mathrm{D}$, and $\left(p_{1}^{*}-t\right)(a-$ $\left.b p_{1}^{*}+c q_{2}^{*}\right)$ from market $\mathrm{F}$, while firm 2 earns $q_{2}^{*}\left(a-b q_{2}^{*}+c p_{1}^{*}\right)+q_{2}(a-$ 
$b\left[q_{2}+t\right]+c p_{1}$ ) (recall that $q_{2}^{*} \geqslant q_{2}$ when firm 2 ties). It can readily be shown that the tying constraint is binding on firm 2 given $p_{1}$ and $p_{1}^{*}$ below. The best-reply prices are $p_{1}=\left[a+c\left(q_{2}+t\right)\right] / 2 b, p_{1}^{*}=\left[a+b t+c q_{2}\right] / 2 b$ and $q_{2}=\left[2 a-b t+c\left(p_{1}+p_{1}^{*}\right)\right] / 4 b$. Solving these equations yields

$$
\begin{aligned}
& q_{2}=\frac{2 a-(b-c) t}{2(2 b-c)}, \\
& p_{1}=\frac{a}{2 b-c}+\frac{c(3 b-c) t}{4 b(2 b-c)},
\end{aligned}
$$

and

$$
p_{1}^{*}=\frac{a}{2 b-c}+\frac{\left[(2 b-c)^{2}+b c\right] t}{4 b(2 b-c)} .
$$

The first important point to note is that firm 2 (which ties its prices) chooses exactly the same prices as at the bilateral tied market equilibrium [(14) is the same as (9)]. Firm 1 (which segments the markets) charges the same average price as firm 2 , but absorbs some of the cost difference, $t$. This implies that the average price is higher in market $D$ and lower in market $F$ than at either of the two bilateral cases.

Equilibrium consumer prices are shown in Fig. 1 for the different combinations of pricing policies.

Because each firm's avcrage consumer price is still equal to $\bar{p}$ in the cross case, output per firm is still equal to $\chi$. This result follows from the argument used after Property 2 . Hence Property 2 applies to the cross case as well as to both symmetric cases although in the cross case the average consumer price and consumption in each country differ.

In comparison with the bilateral tied market case $(T, T)$, firm 1's profit is higher and firm 2's is the same in the cross case $(S, T)$. Since firm 2's prices are identical in the cross case and in the bilateral tied case, firm 1 can certainly improve upon its tied market profit because the tied price equilibrium is part of its feasible strategy set when it is allowed to segment the markets. Firm 2 has the same producer price in each market and the same total output in both cases, so its profit is the same.

In comparison with the bilateral segmented market case $(S, S)$, firm 1's profits are higher and firm 2's are lower in the cross case $(S, T)$. Firm 2's

\footnotetext{
${ }^{8}$ It can be shown that the asymmetric equilibrium described by (14)-(16) exists if an equilibrium exists for the reciprocal tied markets case. To see this, note first that firm 1 does not wish to deviate since it segments markets and $p_{1}^{*}>t$. Given that profits increase in the rival's price, firm 2 does not wish to deviate and secure only its home market F: in comparison with the reciprocal tying case, it would lose more by giving up market D (because firm 1's price is higher there) and it would gain less in market $F$ (because firm 1's price is lower there).
} 


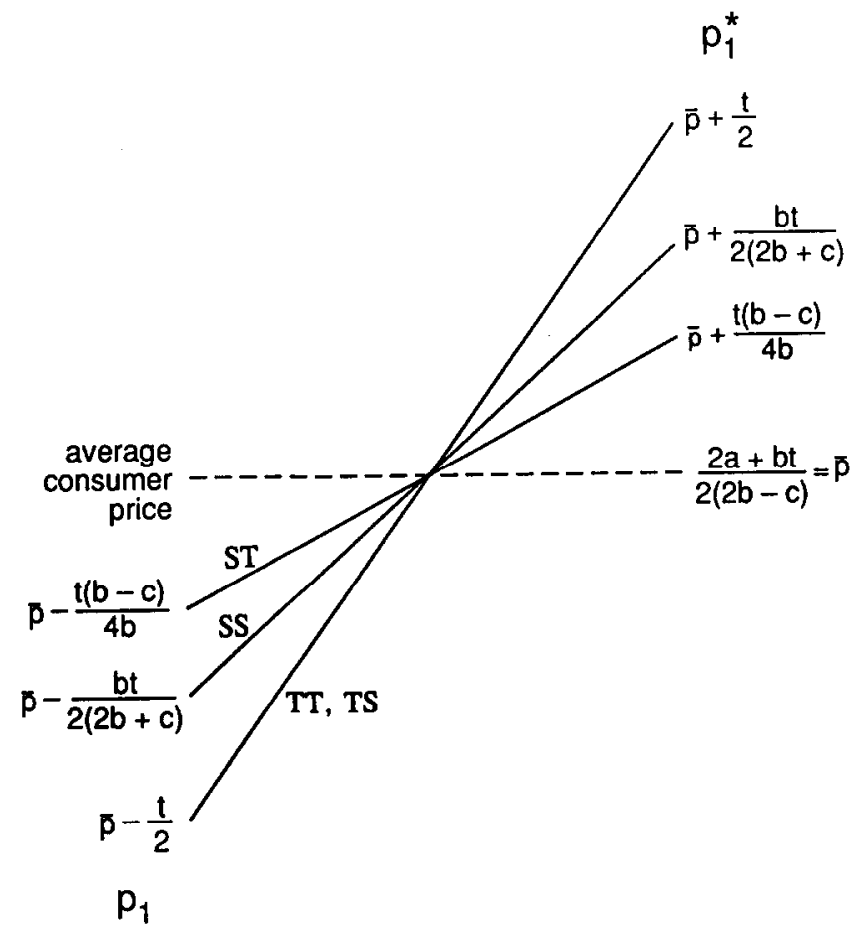

Fig. 1. Comparison of consumer prices set by firm 1 under different price policies. $S T$ means firm 1 segments its markets, whereas firm 2 ties its markets; $T S$ stands for the opposite case.

price spread rises as it moves from segmenting to tying. This shifts demand into firm 1's domestic market, and out of firm 1's foreign market at rate $c$ in both cases. The domestic market involves a greater mark-up, so that firm 1's profit would go up even if it kept the prices of the bilateral segmentation equilibrium. It can do even better by optimizing its prices, and will choose to raise its domestic price while lowering its foreign price (since the price reaction functions slope up). Lastly, firm 2's profit is the same as under bilateral tying and Proposition 1 shows that bilateral segmentation is more profitable than this. The results above are summarized in Table 1 , where the equilibrium profits take only three different values denoted $L, M$, and $H$, with $L<M<H$. The table underlies the proof of the following proposition.

Proposition 3. If governments wish to protect domestic firms, then the only case that cannot be an equilibrium is \{no law, no law\}.

Antidumping legislation directly effects the nature of competition by altering the pricing policy of the rival firm. Thus it is government $F(D)$ that 
Table 1

Firm profits, $L<M<H$. In each cell, the first entry represents government F's payoff (firm 2's profit)

\begin{tabular}{llllll}
\hline & & \multicolumn{3}{c}{ Government D } \\
\cline { 2 - 5 } & $\begin{array}{l}\text { Law } \\
(2 \text { ties })\end{array}$ & & \multicolumn{2}{l}{$\begin{array}{l}\text { No law } \\
(2 \text { segments })\end{array}$} \\
\hline \multirow{3}{*}{ Government F } & $\begin{array}{l}\text { Law } \\
(1 \text { tie })\end{array}$ & $L$ & $L$ & $H$ & $L$ \\
\cline { 2 - 6 } & $\begin{array}{l}\text { No law } \\
(1 \text { segment })\end{array}$ & $L$ & $H$ & $M$ & $M$ \\
\hline
\end{tabular}

determines whether firm 1 (2) must tie its sales or not. ${ }^{9}$ Each firm would like its rival to have to tie its prices. Strict enforcement of antidumping legislation will do just that. Therefore each firm has the incentive to lobby its government for a law that effectively forces the competition to tie their markets. If the firms in both countries are successful, the result is that the firms are worse off.

From the consumer point of view, different cases are characterized by different price spreads and different average prices. Comparing reciprocal tying with the cross case where only firm 2 ties, consumers in market $D$ are definitely worse off since they face a higher price for good 1 ; consumers in market $F$ are definitely better off since they face a lower price for good 1 . In both markets the price of good 2 remains unchanged. Similarly, in a move from the reciprocal segmented case to $(S, T)$, both prices in market D rise while both prices in market $F$ fall. This implies that consumers in $F(D)$ are better (worse) off. Consumer surpluses are summarized in Table 2 . The proof of the next proposition follows directly from Table 2 .

Proposition 4. If the sole objective for governments is to maximize consumer surplus, the unique equilibrium is for both governments to adopt no law.

Table 2 embodies a prisoners' dilemma situation: consumers everywhere are better off if both governments could agree to impose antidumping legislation. If only one country imposes a law, consumers there are worse off than without a law. Consumers in the other country are in the best of all situations because prices there are lowest, since the domestic firm will set a

\footnotetext{
${ }^{9}$ Table 1 also shows that if firms could credibly commit to a particular pricing strategy ( $S$ or $T$ ), then the unique (two-stage) Nash equilibrium would be $(S, S)$ in the first stage since $S$ is a dominant strategy for firms. To see this result, replace governments $F$ and $D$ by firms 1 and 2 , respectively, and read Table 1 in the opposite manner from usual (i.e. firm 1's payoffs are given second). Even if firms could commit to a price policy, they would choose segmented markets, which is the outcome in the absence of any commitment.
} 
Table 2

Consumer benefits, $V L<L<H<V H$. Consumer surplus in $\mathrm{F}$ is given first in each entry

\begin{tabular}{llllll}
\hline & & \multicolumn{3}{c}{ Government D } \\
\cline { 3 - 6 } & $\begin{array}{l}\text { Law } \\
(2 \text { ties })\end{array}$ & & \multicolumn{2}{l}{$\begin{array}{l}\text { No law } \\
\text { (2 segments) }\end{array}$} \\
\hline \multirow{3}{*}{ Government F } & $\begin{array}{l}\text { Law } \\
(1 \text { tie })\end{array}$ & $H$ & $H$ & $V L$ & $V H$ \\
\cline { 2 - 6 } & $\begin{array}{l}\text { No law } \\
\text { (1 segment) }\end{array}$ & $V H$ & $V L$ & $L$ & $L$ \\
\hline
\end{tabular}

low domestic price in order to avoid having too high a price in the foreign market, and this low price elicits a low price from the competition. Consumers actually benefit from bilateral laws if the alternative is no law at all.

Proposition 5. If the objective function of the governments is social surplus maximization, the unique equilibrium is for both governments to adopt no law. This result holds whether $t$ is a resource cost or a tariff.

Proof. First consider the case when $t$ is a resource cost. If one government adopts an antidumping law, the other is better off by not adopting a law since its firm's profit is the same regardless (Table 1 ) but its consumers are better off (Table 2). We must now show that no law is a strict best response to no law. Social surplus in market $\mathrm{D}$ is given by

$$
W=V\left(p_{1}, p_{2}\right)+p_{1} x_{1}+\left(p_{1}^{*}-t\right) x_{1}^{*} .
$$

We know that a move from law to no law, when the rival government $\mathrm{F}$ imposes no law, causes $p_{2}^{*}$ to rise [cf. (4) and (14)]. Since firm 1 discriminates before and after, its profit earned in market $\mathrm{F}$ rises $\left[\left(p_{1}^{*}-t\right) x_{1}^{*}\right.$ goes up]. The remaining terms in $W$ are $V\left(p_{1}, p_{2}\right)-p_{1} V_{1}$. Despite the fact that $p_{1}$ and $p_{2}$ are both lower in the absence of tied sales, it is possible that this expression (domestic consumer surplus plus home firm's profit from the home market) be higher when the foreign firm ties. We therefore need to use the full expression (17). It is shown in the appendix that total domestic surplus is higher without an antidumping law. The only equilibrium is therefore to have no laws.

Now consider the tariff case. It suffices to show that tariff revenues are strictly higher when no law is chosen; or equivalently (since $t$ is fixed), that import volume is greater. If both firms tie sales and $F$ then relaxes its law, $p_{2}^{*}$ is unchanged, but $p_{1}^{*}$ falls so that $x_{1}^{*}$ rises (imports increase). If now D relaxes its law, allowing firm 2 to price discriminate, then $p_{2}$ falls, but so does $p_{1}$. Recalling $x_{2}=a-b p_{2}+c p_{1}$, imports into $\mathrm{D}$ rise if $p_{2}$ goes down at 
least as much as $p_{1}$ decreases. Now, $p_{2}$ falls by $(b+c) t /(2 b+c)^{2}$ and $p_{1}$ falls by $c t(b+c) / 4 b(2 b+c)$. Since $c \leqslant b, p_{2}$ falls more than $p_{1}$, ensuring that imports in market $D$ rise.

In conjunction with Proposition 2, Proposition 5 implies that the noncooperative equilibrium is a prisoners' dilemma situation when $t$ represents a pure resource cost. ${ }^{10}$ Thus the non-cooperative equilibrium is not Pareto efficient in the transport cost case, but it is Pareto efficient when $t$ represents a tariff rate. This result is discussed further in the conclusions.

Propositions 3-5 correspond to very different weights on consumer surplus and profit in the government objective function. If we let $\mu \in[0,1]$ be the relative weight on firm profit, then we have considered the cases $\mu=1, \mu=0$, and $\mu=1 / 2$ in the propositions. Other cases could be considered. The case $\mu \rightarrow 1$ with $\mu<1$ is perhaps the most interesting. This corresponds to governments putting very small weight on consumer surplus, but this is enough to eliminate $\{l a w, l a w\}$ as an equilibrium in Proposition 3, because profit remains the same if one government imposes no law but consumer surplus rises. Hence the only equilibria are $\{l a w$, no law $\}$ and $\{$ no law, law $\}$. It remains true that an antidumping law can only arise in a non-cooperative equilibrium when profit has a weight exceeding $1 / 2$ in the government's welfare function.

Many results in industrial organization and in international trade with imperfect competition are sensitive to the assumption used to characterize firm interaction. This is not the case in our model: the equilibrium outcome of the game between governments is the same for a Cournot market game as for the Bertrand one. The argument is summarized below (see Anderson et al., 1993, for more details).

The key property of the Cournot case is that average consumer prices for each firm (although not in each market in the cross cases) are the same for all subgames. Hence Property 2 holds for the Cournot model, and firm 1 has the same prices in each market in the case $(T, S)$ as it does in $(T, T)$ (its average price is the same, and in both cases its price difference is $t$ ).

Since Property 2 holds, the proof of Proposition 1 still holds: profits are greater in $(S, S)$ than in $(T, T)$. Proposition 2 in its entirety follows directly

\footnotetext{
${ }^{10}$ In our model, governments can choose either law or no law. An alternative assumption is that governments can choose the size of the dumping margin of the foreign firm (the dumping margin is $p_{1}-q_{1}^{*}$ for government $\mathrm{F}$ and $p_{2}^{*}-q_{2}$ for government $\mathrm{D}$ ). This renders the problem continuous and is similar to the Bian and Gaudet (1992) treatment of choice of countervailing duties. These authors evaluate the welfare derivative of a duty around the non-intervention point. A similar exercise in our context shows that for $b \geqslant c>0$ there is always a range of transport cost rates, $t$, for which firms trade and, for $t$ not too small, a government which aims to maximize welfare wishes to lower the dumping margin (deviate from SS). These results are qualitatively similar to those of Bian and Gaudet.
} 
from the property that average price is the same in both $(S, S)$ and $(T, T)$, but the price spread is greater in the latter. The original proof uses no other property of the equilibrium.

Proposition 3 concerns the game between profit-maximizing governments. It holds because the matrix of profits has the same structure as Table 1 . The matrix of consumer surpluses is also qualitatively the same as in Table 2, the reason being that consumer prices bear the same ordinal relation as in Fig. 1. As regards Proposition 5 with transport costs, the original argument shows that $(T, T)$ is not an equilibrium. Tedious calculations then show that $(S, S)$ is the unique equilibrium. Lastly, the proof that $(S, S)$ is an equilibrium in the tariff case follows the same lines as before. Therefore all the qualitative results of the Bertrand case carry over to the Cournot case. This is due to the similar mathematical structure of the two problems.

Although the model used in this paper is quite specific, such specificity is required to analyze the two-stage games. Our results provide a useful benchmark and suggest some more general principles. As noted above, results by Smith and Venables support the idea that firms lose when markets are tied, but overall welfare is greater.

\section{Conclusions}

Proposition 5 says that if governments are interested solely in domestic consumer surplus plus home firm profits, and given our assumption that the only instrument available to governments is an antidumping law, then we would expect to have no antidumping laws. ${ }^{11}$ The intuition is that welfare falls by enforcing antidumping legislation since domestic prices rise and this usually decreases the sum of consumer surplus plus the domestic firm's profit in the home market. Domestic prices rise because the foreign firm raises its price to meet the antidumping constraint and the home firm follows suit as competition is relaxed. At the same time the foreign firm cuts its price in its own market to offset excessive pricing in its other market. This causes the domestic firm to lose out in its foreign market. Hence, in this model the only reason for observing antidumping laws enforced as the outcome of a non-cooperative equilibrium is successful lobbying by domestic firms (Proposition 3).

However, Proposition 2 shows that, provided $t$ is a resource cost, social surplus is greater when there are bilateral laws than without them. Thus, lobbying activities by firms leading to antidumping legislation is welfare improving when $t$ is a pure resource cost (provided, of course, that the costs

\footnotetext{
${ }^{11}$ We have assumed throughout the paper that antidumping laws will be strictly enforced so no firm dumps. For an analysis of probabilistic enforcement, see Fischer (1992).
} 
of lobbying are smaller than the difference in social surplus). This is because such laws eliminate price discrimination, and consequently the prisoners' dilemma situation at the equilibria described in Proposition 5. This suggests another interesting possibility: the bilateral use of antidumping laws could be seen as a cooperative agreement on the part of governments to avoid the dilemma. ${ }^{12}$ Not only does GATT allow such laws but, from this viewpoint, should encourage them to be strictly applied. Countries not applying them can be seen in the context of this model as free riders!

Proposition 5 also suggests that countries within a free-trade arrangement are more likely to face a dilemma than those in trading situations where tariffs are a large part of the trade barrier. Thus the incentive for governments to agree collectively to enact legislation restricting price discrimination is likely to be greater with free-trade arrangements (EC, NAFTA) than between trading partners that already impose substantial tariffs on each other. More generally, in a world where tariff barriers to trade are on the wane relative to real barriers, we should expect governments collectively to be more interested in the enforcement of antidumping laws.

\section{Acknowledgements}

We wish to thank three anonymous referees and the Editor for their comments. The first author would like to thank the Bankard Fund for financial support; the second author would like to thank the Social Sciences and Humanities Research Council of Canada.

\section{Appendix}

Proof of Proposition 5.

$$
\begin{aligned}
W & =V\left(p_{1}, p_{2}, Y\right)+p_{1} x_{1}+\left(p_{1}^{*}-t\right) x_{1}^{*} \\
& =Y-a p_{2}+\frac{b}{2}\left(p_{2}-p_{1}\right)\left(p_{2}+p_{1}\right)+\left[p_{1}^{*}-t\right]\left[a-b p_{1}^{*}+c p_{2}^{*}\right] .
\end{aligned}
$$

Let $A \equiv a /[2 b-c]$ and $\Delta \equiv 4 b^{2}-c^{2}$. When both firms segment the markets, $p_{1}=p_{2}^{*}=A+c b t / \Delta$ and $p_{2}=p_{1}^{*}=A+2 b^{2} t / \Delta$ [see (4) and (5)]. Hence $p_{2}-p_{1}=b t /(2 b+c) ; p_{2}+p_{1}=2 A+b t /(2 b-c) ; p_{1}^{*}-t=A+t\left(c^{2}-2 b^{2}\right) /$ $\Delta$; and $a-b p_{1}^{*}+c p_{2}^{*}=b\left(p_{1}^{*}-t\right)$. Thus,

\footnotetext{
${ }^{12}$ The bilateral use of laws can also be upheld as an equilibrium in an infinitely repeated game in the standard manner.
} 


$$
\begin{aligned}
W^{S S}= & Y-a\left(A+\frac{2 b^{2} t}{\Delta}\right)+\frac{t b^{2}}{2(2 b+c)}\left[2 A+\frac{b t}{2 b-c}\right] \\
& +b\left(A+\frac{t\left(c^{2}-2 b^{2}\right)}{\Delta}\right)^{2} \\
= & Y+A(b A-a)+\left[2 c^{2}-6 b^{2}+c b\right] t A b / \Delta \\
& +\left[12 b^{4}-9 b^{2} c^{2}+2 c^{4}\right] t^{2} b / 2 \Delta^{2} \\
= & Y+A(b A-a)+\left[-24 b^{3}+4 b^{2} c+8 b c^{2}\right] t A / 4 \Delta \\
& +\left[192 b^{6}-144 b^{4} c^{2}+32 b^{2} c^{4}\right] t^{2} / 32 b \Delta^{2} .
\end{aligned}
$$

When the foreign firm (firm 2) ties its markets, prices are given from (14)-(16) (with $p_{2}^{*}=q_{2}$ and $\left.p_{2}=q_{2}+t\right)$ as $p_{1}=A+(c / 4 b)[(3 b-c) /(2 b-$ c) $] ; p_{2}=A+[(3 b-c) /(2 b-c)](t / 2), p_{1}^{*}=A+\left[\left(4 b^{2}+c^{2}-3 b c\right) /(4 b(2 b-\right.$ $c))] t ; p_{2}^{*}=A-[(b-c) / 2(2 b-c)] t$. Hence $p_{2}-p_{1}=[(3 b-c) / 4 b] t ; p_{2}+$ $p_{1}=2 A+[(2 b+c)(3 b-c) / 4 b(2 b-c)] t ; \quad p_{1}^{*}-t=A+\left[\left(c^{2}-4 b^{2}+b c\right) /\right.$ $4 b(2 b-c)] t$; and $a-b p_{1}^{*}+c p_{2}^{*}=b\left(p_{1}^{*}-t\right)$. Substituting in (A.1),

$$
\begin{aligned}
W^{S T}= & Y-a\left(A+\frac{3 b-c}{2(2 b-c)} t\right)+\frac{(3 b-c)}{8} t\left(2 A+\frac{(2 b+c)(3 b-c)}{4 b(2 b-c)} t\right) \\
& +b\left(A+\frac{\left(c^{2}-4 b^{2}+b c\right)}{4 b(2 b-c)} t\right)^{2} \\
= & Y+A(b A-a)+\left[-14 b^{2}+7 b c+c^{2}\right] t A / 4(2 b-c) \\
& +\left[68 b^{4}-40 b^{3} c-19 b^{2} c^{2}+10 b c^{3}+c^{4}\right] t^{2} / 32 b(2 b-c)^{2} \\
= & Y+A(b A-a)+\left[-28 b^{3}+9 b c^{2}+c^{3}\right] A t / 4 \Delta \\
& +\left[272 b^{6}+112 b^{5} c-168 b^{4} c^{2}-76 b^{3} c^{3}+25 b^{2} c^{4}+14 b c^{5}\right. \\
& \left.+c^{6}\right] t^{2} / 32 b \Delta^{2} .
\end{aligned}
$$

Subtracting (A.3) from (A.2) yields

$$
\begin{aligned}
W^{S S}-W^{S T}= & {\left[4 b^{3}+4 b^{2} c-b c^{2}-c^{3}\right] A t / 4 \Delta } \\
& +\left[-80 b^{6}-112 b^{5} c+24 b^{4} c^{2}+76 b^{3} c^{3}+7 b^{2} c^{4}-14 b c^{5}\right. \\
& \left.-c^{6}\right] t^{2} / 32 b \Delta^{2} .
\end{aligned}
$$

The first term is positive and the second negative for $b \geqslant c$. Hence $\left(W^{s S}-\right.$ $\left.W^{S T}\right) / t$ is smallest for $t$ as large as possible. We can then use (11) as a sufficient upper bound, so we want to show that $\left(W^{S S}-W^{S T}\right) / t$ is still positive when $t=2 a b /\left(3 b^{2}-c^{2}\right)$. This amounts to

$$
16 B^{6}+32 B^{5}+16 B^{4}-8 B^{3}-13 B^{2}-2 B+3>0,
$$


where $B \equiv b / c>1$, so the desired condition clearly holds.

\section{References}

Anderson, S.P., N. Schmitt and J.-F. Thisse, 1993, Who bencfits from antidumping laws?, University of Virginia Discussion Paper 256.

Bian, J. and G. Gaudet, 1992, Anti-dumping laws and oligopolistic trade, mimeo, Université du Quebec à Montréal.

Brander, J.A. and P.R. Krugman, 1983, A reciprocal dumping model of international trade, Journal of International Economics 15, 313-321.

Davidson, R., M. Dewatripont, V. Ginsburgh and M. Labbé, 1989, On the welfare effects of anti-discrimination regulations in the EC car market, International Journal of Industrial Organization 7, 205-230.

Fischer, R.D., 1992, Endogenous probability of protection and firm behavior, Journal of International Economics 32, 149-163.

Fisher, E. and C. Wilson, 1988, International duopoly with tariffs, mimeo, Cornell University. GATT, 1991, Trade policy review. The European Communities, vol. 2 (GATT, Geneva).

Gruenspecht, H., 1988, Dumping and dynamic competition, Journal of International Economics, 25, 225-248.

Hotelling, H., 1929, Stability in competition, Economic Journal 39, 41-57.

Jackson, J.H. and E.A. Vermulst, 1989, Antidumping law and practice (The University of Michigan Press, Ann Arbor, MI).

Mertens, Y. and V. Ginsburgh, 1985, Product differentiation and price discrimination in the European Community. The case of automobiles, Journal of Industrial Economics 34, 151-166.

Prusa, T.J., 1992, Why are so many antidumping petitions withdrawn?, Journal of International Economics 33, no. 1/2, 1-19.

Smith, A. and A.J. Venables, 1988, Completing the internal market in the European Community, European Economic Review 32, 1501-1525.

Staiger, R.W. and F. Wolak, 1989, Strategic use of antidumping law to enforce tacit international collusion, mimeo, Stanford University.

Tharakan, P.K.M., 1991, The political economy of anti-dumping undertakings in the European Communities, European Economic Review 35, 1341-1359.

Venables, A.J., 1990a, Tariffs and subsidies with price competition and integrated markets; The mixed strategy equilibrium, mimeo, Univerity of Southampton.

Venables, A.J., 1990b, International capacity choice and national market games, Journal of International Economics 29, 23-42.

Vermulst, E.A., 1987, Antidumping law and practice in the Unites States and the European Communities: A comparative analysis (North-Holland, New York, NY). 